\title{
Perception of thermal comfort in the enclosed transitional space of tropical buildings.
}

\begin{abstract}
The enclosed lift lobby distinguishes itself as a unique form of region categorised under building transitional spaces. This paper reports on an evaluation of thermal comfort conditions in a prominent transitional space in buildings which is the enclosed lift lobby of an educational institution in Malaysia, using field survey which included objective measurement and subjective assessment. The temperature set-point of air conditioner was increased and maintained at $26^{\circ} \mathrm{C}$ to investigate the human thermal perceptions in the enclosed region. Comparison was made on the percentage of thermal sensation, preference, acceptability and general comfort votes obtained from field survey. The outcomes clearly indicated that the human thermal perception in the enclosed lift lobby would be directly proportional to the level of human occupancy, and any sudden temperature change could lead to thermal discomfort of occupants. The respondents generally preferred to have cooler environment, rather than warmer one. Also, comfortable temperature can be obtained even with higher air conditioner thermostat settings. These findings may serve as a guide for building operators in the tropics to control the energy consumption of cooling equipment attached to the enclosed transitional spaces.
\end{abstract}

Keyword: Enclosed lift lobby; Field survey; Transitional spaces; Thermal comfort; Tropics. 